\title{
Marketing Jordan as a Regional Medical Service Center (View Point of Employee)
}

\author{
Mahmud Aqel Abu Dalbooh ${ }^{1}$ \\ ${ }^{1}$ Head of Marketing Department, Irbid University, Jordan \\ Correspondence: Mahmud Aqel Abu Dalbooh, Assistant Professor of Marketing, Irbid University, Jordan. Tel: \\ 962-77-740-3051. E-mail: m_agel_dlb@yahoo.com
}

Received: December 22, 2014 Accepted: March 2, 2015 Online Published: May 31, 2015

doi:10.5539/ijms.v7n3p107 URL: http://dx.doi.org/10.5539/ijms.v7n3p107

\begin{abstract}
The author has conducted the study on the reality of medical sector in Jordan within title "The availability to marketing Jordan as regional medical care service center". As researcher I applied the study on Jordanian medical sector for knowing the resources of basics medical industry. The study contains theoretical part and methodology, results and analysis, recommendations, in which there are three independents variables (medical care in Jordan: government, private, military sectors, and natural sites, government role) dependant variable (marketing Jordan regionally as medical service center). The study aimed to explore the role of government as: Jordan maybe promote medical sector regionally, make up the industry of medical sector and maximize the profit. The study explore there are many medical services in Jordan for investment as a regional attraction customer center.
\end{abstract}

Keywords: medical service, medical tourism, experience, infrastructure, regional center, government role

\section{Introduction}

God has given Jordan geographical middle location, the temperate climate and unique human resource, excellent infrastructure and place for the mentalist tourism to think in God's creation. Jordan enjoys unique climatic and geographical diversity wither the mountain and the valley, plain and the desert and the Jordan Valley rivers and the resorts. It is also unique in its cultural diversity.

The medical aspect in Jordan has numerous types and goals. Due to the variation and available medical care diversity also successive civilizations have worked to exploit the medical benefits in Jordan. It could be said that medical care in Jordan is depended on the goals, culture, costs, image, promotion, medical technology.

\subsection{The Importance of the Study}

Medical care has a higher importance and one of the main sectors in Jordan, Gross demostic product (GDP), we May reach to say that medical care attractiveness is the petroleum of Jordan, Enable it to be get up and moving to the professionalism at medical marketing in specialized aspects At the regional level (medically). Jordan need to study medical resources available and find ways to utilize them and enhance their productivity and maximize the proceeds.

\subsection{Problem Study}

The medical care sector in Jordan faces several obstacles (Jordanian Ministry of health, Annual Report 2009) including

- The way of exploitation of medical resources available in Jordan in the best methods

- $\quad$ The level of interest in the infrastructure of the medical care sites

- The role of Government in the development of medical care to be regional attractiveness

- $\quad$ Medical care in Jordan suffers from the purchasing cost 


\subsection{Study Objectives}

Study aimed to know the following:

- $\quad$ Knowing the obstacles that face the medical tourism sector in Jordan (Sam awe 2008)

- $\quad$ Determine the extent the contribution of medical tourism in GDP in Jordan

- $\quad$ Knowing the medical tourist positions in Jordan

- $\quad$ Define medical tourism in Jordan to see the possibility of developed and exploited for marketing Jordan regionally for medical tourism (WTO. 2009)

\section{Methodology of Research}

Researcher, who adopted the descriptive and analyzing study of the medical care in Jordan, based on the study and knowledge the views of the workers in the medical sector, such as the Ministry of health and the medical care institutions, social institutions. That also the author depended on both primary sources of information through interview members of the study sample and secondary sources as Bulletins, reports, previous studies, and books.

The limits of the study:

A - Temporal: Statistics study and analysis of availability to marketing Jordan as medical center during the period (2007-2011)

B- Spatial: study the medical care resources, such as: hospitals, medical city, and medical institutions in Jordan.

\subsection{Previous Studies}

1) Bthathaw study, Aldlaain (2011), entitled "electronic marketing and medical tourism in Jordan".

This study aimed to identify the size and the importance of the medical care sector. Also the contribution of developing health industry; On the other hand, showed that the medical care sector constitute an important tributary of the national economy of Jordan. And we can exploit it better, the importance of health care information systems to assist in the marketing Jordan at the external level (Regionally).

The study came out a range of recommendations, including that we need to marketing Jordan externally and focusing on the development of medical care in various fields, marketing of medical care in Jordan through the information system GPRS too.

2) Ismail study Shaker and Sheikh Mustafa, (2010) entitled "The influence of the marketing of Jordanian medical services on the growth of the medical tourism locally and regionally".

This study aimed to know the impact of marketing of the Jordanian medical services on medical tourism and the role of medical tourism to increase the GDP of Jordan.

On the other hand it showed that there is a positive relationship between hospitality and the growth of medical tourism. And there is a positive relationship between the quality of medical service and increase the number of tourists. Also there is a positive relationship between the marketing mix and growth in medical tourism.

The study recommended the Marketing Managers in Jordanian hospitals to focus on the quality of medical services and to Re-pricing of medical services and constantly, to maintain a competitive environment and attract tourists for the purposes of treatment.

3) Mosharbash study, Dime (2008), entitled "Factors affecting the satisfaction of tourists from medical tourism in Jordan".

This study aimed to know the extent of the satisfaction of tourists on infrastructure and metadata services and the extent of medical tourism programs to attract tourists (customers). We can notice that the study showed the low satisfaction of tourists for tourist services and facilities, the weakness of medical tourism programs, and the low level aspects of the attractions of the Curative aspects. Where the study recommended of rehabilitation of infrastructure and tourist facilities in the meta-therapeutic, Design programs for medical tourism fit with the requirements and the needs and desires of tourists and design of promotional programs for marketing of medical tourism externally.

4) Ali Khalil study (2007), entitled "The Medical Tourism in Jordan, Case Study of Yemenis patients in Jordanian hospitals".

This study aimed to know the importance of medical tourism in Jordan and the extent of Yemenis patient satisfaction for therapeutic services in Jordan. The study showed the nature of the therapeutic services that 
patients are looking for, Possibilities and medical capabilities available in Jordan, and The volume of employment opportunities offered by medical tourism.

At the end the study recommended at the need to focus on medical tourism and diversification, the importance of investing in areas with a therapeutic means, and Focusing on the privacy of the Dead Sea, due to the volume of material available for the treatment of patients (Sea water, Mud, salts).

5) Aldmour and Alnserat, (2004) entitled "The impact of the marketing mix to attract Arab patients for treatment in Jordanian hospitals".

This study aimed to know the impact of the elements of the marketing mix to serve the medical tourism on the decisions of Arab patients to choose Jordanian hospitals. The impact of demographic factors on the decisions of patients and determine the place of treatment and showed that there is a trace of both education and age on the decision of the SPV therapeutic service in Jordanian hospitals.and recommended Jordanian authorities competent to increase the number of promotional campaigns for medical tourism in Jordan in the Arab countries.

6) Maia, Kuala study (1995), entitled "Geography of medical tourism in Jordan".

The study aimed to know the areas with Therapeutic nature in Jordan, The number of tourists Jordanians and non-Jordanians, and Determine the nature and varieties of diseases that can be healing.

The study showed that Jordan has dramatically sites for medical tourism, and Jordan has available resources for internal and foreign tourism. At the end the study recommended of the need to improve the tourist areas of therapeutic nature, Activating the medical role and Exploitation of resources therapeutic larger and promoting therapeutic areas in Jordan, in both internally and externally.

\subsection{Theoretical Part}

Introduction:

We can say that tourism achieved two main goals the mental tourism as God truly say "Travel through the land and observe" Annam - verse 69 - in order to think of God's creation and the laws of the universe. But the second objective is investment tourism as God truly say (Travel through the earth and see) -verse 20- AlAnkabut. God say (God creat human being in the best standers) al-teen sora, verse 4, so looking for the requirements of the individual in the life has been multiple forms of health care and medical entertainment in the aspects of education, welfare, treatment, visits.

Many of the developed countries interesting in developing medical care industry, because no longer only as a sector of economic in general, but turning this concept to introduce tourism as an industrial sector and vital state facilities therefore medical care develop the concept of investment and industry, and then to the marketing of the medical care industry regionally. Jordan would also take serious thinking in development of the medical care sector as in the countries of the world to using methods and multiple ways in order to increase the national income of Jordan and try to gain access to the level of this sector of the medical industry both internally and externally, regionally and internationally.

God gives Jordan many medical blessings in multiple areas including: medical city, hospitals, medical centers, profissonal medical institutions, medical nature sites, and medical expertise.

Available Services for medical center in Jordan:

1) Government medical sector: Jordan consider one of the countries with a temperate climate in either summer or winter, one of the Mediterranean countries with wonderful situation, there are :a good medical infrastructure, medical city, hospitals, medical center, the elements of attractions according to climate variability and this means the ability to achieve diversity of medical care.

2) Private medical sector: The Jordan has been care with a medical aspect, because human being in Jordan is firstly. Health insurance system, cooperation with world health organization, the private sector attitude to investment in medical industry seam as soon as progress countries. There are many reasons: funds, capital, human beings, expeirance, infrastructure, medical technology, attitudes for investing, strategies, policies, plans, programs, and releations.

3) Military medical sector: It has a big city, many hospitals, and medical centers.

4) Nature medical sites: Jordan consider one of the privileged sites of historical and cultural diversity and the Romans, Jobsites and Muslim civilizations that have left their impact on the religious aspects, such as mosques, temples and silos, In architecture, we find squares and amphitheater of Jerash, Um Quiz, Um Algoma and Madaba. Amman as well as witness on that, in the infrastructure we can see irrigation canals 
and drainage channels in Jerash and the Roman amphitheater in Amman. On the defensive side can see the AlRabd castle UM Quiz and Shobak, as well as cross the time we observe the Islamic civilization in the Umayyad and Abbasid and Turkish castles and palaces Along the expanse of geography Jordan., after that there are medical sites as: dead sea, Jordan river (holy water), agape gulf, hot water.

A-religious sites: Religious sites witnessed on successive civilizations on Jordan where divine messages was not far from that, the place where Jesus has been (baptized) in the River Jordan, the holy Jordan water and the bath located on the east side of the Jordan River, and the role of Christian worship in Madaba, Mount Nebo, and churches Rehab, Um Quiz, Jerash, Amman, witness to this. On the Islamic side religious places is witnessing on the Islamic civilization and all ages as Rashid, Umayyad, Abbasid, Turkish and we see it in the shrines of companions in Karaka, Almazar, Muta, Wade Musa, Jordan Valley, Irbid, as well as Turkish castles and forts and outposts (the places of the security).

B-tourist sites: Jordan has many sites of tourism nature, where aesthetic and attractiveness sites, ease of nature and freshness of water and there are reserves tree in Ajloun and Rajab and Arjan, and Deben, Jerash, and animal reserves and wild birds in Alazrag, Shobak, Aqaba and Reserves of rare plants, In addition to the entertainment sites King Hussein Park and Jubeiha, and tourist resorts in Deben and Guspn Alston, and positions that deal with desert tourism, such as the desert of Rum and Alazrag desert, where Sunbathing and walking tourism on sand and mountain climbing and playing with sand. In addition to that the tourist sites in the therapeutic nature at hamma and Alshunah and the dead Sea and Main and Ofra.

C-water sites: Jordan has many watering historical sites, religious and therapeutic. This country contains numerous sources of water in it and that tourists can benefit them, according to the religious belief for the Christians point of view all over the world that the waters of the Jordan River is (sacred) in addition to what was adopted by (the Vatican and the World Council of Churches) the specificity of the Jordan River and the sanctity given (for the baptism of Christ) by (John the Baptist in the Jordan River), In addition to providing hot water baths in Alshunah and Hamah and Ofra Main Falls and Aremeimin Valley Shalala and not to forget the Dead Sea which is the lowest point on the earth's surface, $402 \mathrm{~m}$ below sea level.

5) Government role: attitudes, strategies, policies, Jordanian human nature, security

A: government Attitudes: to enhance by medical sector in not effectively witch face lake of (promotion budget, strategies, policies, and plans)

B- Jordanian human nature: It is no longer a secret to anyone that Jordanian is a model (human) in the wonderful tolerance, cooperation and magnanimity, generosity, hospitality and warm reception and respect visitors, whether tourists or visitors or delegates formally or newcomer, And that there are customs and traditions and customs respected by the Jordanian man Rooted historical tradition of Jordan, and these values are as valuable can we develop to reach the value-added that is a source of wealth, a tourist from the place of religion, Prophet Muhammad peace be upon him said (was sent to complete morals), This is characterized by Jordanian, which is a cause for pride so Can marketing and promotion of Jordan through his informed and educated and sincere and the secretary and the civilized and privileged consistently man and this (scarcity) which is characterized by Jordanian all else in contemporary societies is a source of attraction and excellence.

C- Security:- It is one of the most important needs that human are looking for, especially foreign tourists, and this is what is available in Jordan all the time so thanks to God and then the institutions responsible of security and care about the tourist as welcomed guest according to norms, customs and traditions of Jordan. Jordan can not be a tourist marketing without this important factor because the requirements of the tourists had exceeded his basic needs and desires reached the stage and details, including the requirements of the tourism product add a comprehensive quality.

\section{Diseases that can be healing in the Medical sector:}

- $\quad$ Rheumatism diseases, Joints Diseases, Diseases of the glands, Skin diseases.

- $\quad$ The nervous system diseases, the chest diseases, Diseases of osteoporosis, rickets, Psoriasis Disease, Respiratory system Diseases.

\section{Materials that can be produced from therapeutic sites:}

- $\quad$ Salts such as calcium, magnesium, sodium, zinc, potassium, these salts can Therapeutics alone or more.

- $\quad$ Sulfur water, Salt water, alluvial materials (mud) from the Dead Sea, sediment water baths, Deposits of water waterfalls. 


\section{Materials that can be manufactured as therapeutic product:}

- $\quad$ Creams, Make-up, Skin protectors, Salts.

- $\quad$ Holy water from the Jordan River, are produced, and sold to cure in order to be blessed.

Table 1. The numbers of medical treatment

\begin{tabular}{llllll}
\hline Year & 2007 & 2008 & 2009 & 2010 & 2011 \\
\hline Number of medical tourist & 370288 & 568476 & 536588 & 640396 & 684444 \\
\hline
\end{tabular}

Source: Jordanian information center.

Independent variables
medical care in Jordan
1- government medical sector
2- private medical sector
3- military medical sector

Figure 1. The model of study

\section{Data Collection Method}

Data were collected in two ways: first was Primary data: the questionnaire is adopted and distributed to customers to find out the extent of their satisfaction about marketing Jordan as regional medical center and the second were Secondary data: Adoption of references, periodicals and websites.

A questionnaire was sent to a number of professors and professionals for arbitration; the researcher has conducted a survey by distributing (2) questionnaires to (19) medical sites. Of which, (29) questionnaires were retrieved in the first time and (33) were retrieved in the second where the percentage of the questionnaire stability was $(83 \%)$.

\subsection{The Study Population and Sample}

The study population consists of all the employees medical in the operating in Jordan by (5634) employee. Given the difficulty of the inclusion of all workers, for reasons of lack of time, the researcher selected a sample of the study population by $(5 \%)$ by using the random stratified sample method where the study sample consisted of (281) employees. After determining the study sample, (281) questionnaires were distributed on the study members. Questionnaires were retrieved by $(100 \%)$ and six questionnaires were excluded for non- suitability for practical purposes of statistical analysis due to lack of information contained therein (275) which analyzed. The following is a detailed description of the personal characteristics of the study sample, as shown in table (4).

\subsection{Study Hypotheses}

The study hypotheses have been formulated based on the problem and variables of the study; the hypotheses were the following:

The first major hypothesis:

H01: There is not statistically significant relationship at $(\alpha \leq 0.05)$ between the medical elements and its dimensions (government sector, private sector, malitary sector, natural medical sites, government role) and marketing Jordan as regional medical center.

H11: There is not a statistically significant relationship at $(\alpha \leq 0.05)$ between the government medical sector and marketing Jordan as regional medical center.

H12: There is not a statistically significant relationship at $(\alpha \leq 0.05)$ between the private medical sector and marketing Jordan as a regional medical center.

H13: there is not a statistically significant relationship at $(\alpha \leq 0.05)$ between the medical military sector and marketing Jordan as a regional medical center. 
H14: there is not a statistically significant relationship at $(\alpha \leq 0.05)$ between the nature medical sites and marketing Jordan as a regional medical center.

H15: there is not statistically significicant relation at $(\alpha \leq 0.05)$ between the government role and marketing Jordan as a regional medical center.

\section{The study tool:}

To answer the questions of the study and test its hypotheses, the researcher prepared a questionnaire for this purpose depending on the literature on market and functionality, as well as previous studies relevant to the subject of this study. The first part of the questionnaire contained personal variables, while the second part deal with the independent variables represented by the (dimensions of medical sector), while the third part addressed the dependent variable (marketing Jordan as a medical regional center). The items of the tool as a whole aimed to evaluate the study sample and their estimation.

\section{The Validity, reliability of the study tool:}

To verify the Face, internal content of the questionnaire, it was displayed in its initial picture to arbitrators specialized in the field of market and business management in the Jordanian universities, in order to figure out their views, comments and estimation of the suitability of the items of the questionnaire to the study. In the light of the observations and suggestions of arbitrators, the wording of some items has been modified, some items were deleted because of its repetition and unsuitability with the themes addressed by the study tool, and some items were added and linked with similar items making the study tool own a high validity to be applied on the members of the sample study. after confirming the validity of the study tool and applying it on the study sample consisting (275) male and female employees and for purposes of verifying the internal consistency of the items of the questionnaire related to the study variables, Cranach's alpha coefficient was applied; Table 3 illustrates. data that obtained through the application of the study tool on the sample it considered valid for the purposes of statistical analysis and for calculating the statistical indicators for the purpose of answering the questions of the study and testing its hypotheses .

\section{Statistical treatment:}

After the researcher had finished from collecting data on the variables of the study, some statistical indicators and methods in the Statistical Package for Social Sciences (SPSS) were used so as to process the data that have been obtained through the field study. In particular, the following statistical methods have been used:

1 - The arithmetic mean: It is used to identify the level of the severity of the answer on the items of the questionnaire.

2 - The standard deviation: It is used to determine the dispersion of the study sample answers about the values of the arithmetic means.

3 - Cranach's alpha coefficient: It is used to test the internal consistency of the items of the study tool used to measure the variables included in the study.

4 - One-Sample Kolmogorov-Smirnov test: This test is used to verify that the study tool data are subject to the normal distribution or not.

5 - Variance Inflation Factors (VIF) test: This test is used to check for the existence of Multi -co linearity between the independent variables.

6 - Spearman Correlation coefficient: This test is used to measure the relationship between the independent variables and the dependent variable.

7 - The Stepwise multiple linear regression analysis: It is used to measure the impact of the independent variables (medical sector dimensions) on the dependent variable (marketing Jordan as a medical regional center).

8 - $\mathrm{t}$-Test: It is used to test the hypotheses of the study to ensure the statistical significance of the results that have been reached through the application of multiple linear regression analysis.

\subsection{Data Analysis and Discussion of the Results}

The results of the statistical analysis obtained through using the SPSS presented.

Before answering the questions of the study and testing its hypotheses, it is important to check the distribution of the data of the study and whether the data are subject to the normal distribution or not? This is done through testing the following statistical hypothesis:

$\mathrm{H} 0$ : The study data is subject to the normal distribution. 
H1: The study data is not subject to the normal distribution.

To test the previous statistical hypothesis, One-Sample Kolmogorov - Smirnov Test was used, as illustrated. The value of $\mathrm{z}$ is 1.96 at $(\alpha=0.05)$ and the 2-tailed test.

It is evident from the final results that all the calculated values of $(Z)$ for the study variables are represented by (customers orientation, competitors orientation, and the integration and coordination between functions ) is less than the tabulated value of $(Z)$ amounting to (1.96). Furthermore, all the statistical values are greater than the level of significant o linearity between the dimensions of medical sector represented in (government, private, military sectors and natural sites, government role). What confirms this is the values of (VIF) calculated for the dimensions listed; all these values are less than the critical value of the test amounting to (5). After it was ascertained that the distribution of the data of the study tool is subject to the normal distribution and the fact that there is no Multi co linearity between (the dimensions of medical sector, it has become possible to perform all the descriptive statistics ( arithmetic means, and standard deviations ), as well as testing the study hypotheses.

In order to facilitate displaying the results of the study, it has been classified according to the sequence of questions and assumptions contained therein.

\section{First: the results related to answering the first question:}

What is the level of the study sample evaluation of the marketing Jordan as a regional medical center and its dimensions? The first question of the study, the arithmetic means, standard deviations and the relative importance of the level of the study sample evaluation of the the government medical sector and its three dimensions were calculated in order to determine the level of severity of each answer on the dimensions items as well as the standard deviations for the purpose of diagnosing the extent of the dispersion of answers from their arithmetic means.

The degree of approval of the study sample has been determined at three levels (low, medium, and large), which was calculated according to the following relationship:

Approval degree $=($ the highest value of the scale - the lowest value of the scale) $/$ number of levels $=(1-5) / 3=$ 1.33

Thus, the degree of approval of the study sample on the items was as follows:

Low degree $=1+1.33=2.33$, Medium degree $=2.34+1.33=3.67$, Large degree $=3.67+1.33=5$

It is evident from the results contained, that the evaluation of the study sample of marketing Jordan as a regional medical center and its dimensions?

And dimensions, and for each item of the dimension, was as follows:

\section{1: government medical sector}

Table (3) evaluation study, shows that has a mean (2.95) and standard deviation (.886) and came in the first rank

\section{2: private medical sector}

Table (3) shows that the evaluation of the study sample for this dimension was (moderate), where the items of this dimension ranged between (large and medium) with arithmetic means (2.95). That "hospitals, medical centers, professional centers" came second rank with a standard deviation of (.861).

\section{3: military medical sector}

Table (3) shows the items of this dimension (hospitals, medical city, centers) came in third rank with a mean (2.78) and SD (.822) and came forth rank

\section{4: natural medical sites}

Table (3) shows the items of this dimension (religious sites, tourism sites, watering sites) came in third rank with a mean (2.94) and SD (.856)

\section{5: government role}

Table (3) shows the items of this dimension (religious sites, tourism sites, watering sites) came in fifth rank with a mean of (2.77) and SD (.776)

First: The results related to answering the second question:

What is the level of the study sample evaluation for marketing Jordan as a regional medical center? 
To answer the second question of the study, the arithmetic means, standard deviations and order were calculated for the level of estimating the study sample for each item of the variables.

\section{Second- Results of testing the study hypotheses:}

The following is a detailed explanation of the results of testing.

H11: there is not a statistically significant relationship at $(\alpha \leq 0.05)$ between the government medical sector (hospitals, centers, medical city) and the marketing Jordan as medical regional center.

H12: there is not a statistically significant relationship at $(\alpha \leq 0.05)$ between the private medical sector (hospitals, centers), and the marketing Jordan as medical regional center.

H13: there is not a statistically significant relationship at $(\alpha \leq 0.05)$ between the military medical sector (hospitals, centers, medical city) and the marketing Jordan as medical regional center.

H14: there is not a statistically significant relationship at $(\alpha \leq 0.05)$ between the natural medical sites (religion sites, medical sites) and the marketing Jordan as medical regional center.

H15: there is not a statistically significant relationship at $(\alpha \leq 0.05)$ between the government role (religion sites, medical sites) and the marketing Jordan as medical regional center.

In table (8) test the validity of hypothesis, the Stepwise Multiple Linear Regression Analysis was used in order to measure the availability of (the dimensions of medical sectors)

Table (4) shows that the value of (correlation) equaling $(.842, .733)$ is very strong, as well as the value of statistical significance amounting (0.000), which is less than the level of significance $(\alpha=0.05)$; therefore, the null hypothesis (H0) is rejected, which indicates to the validity of the model; accordingly, there is an availability for marketing Jordan as a medical center.

Based on the above, it has become possible to use the Stepwise Multiple Linear Regression Analysis in order to measure that.

A - Regression coefficients $(\beta)$ as .880 , (very strong) table (8) of the dimensions of the marketing Jordan as a regional medical center are consistent; therefore, there is a statistically significant impact at the level of significance $(\alpha=0.05)$ for the dimensions listed on the regional center. What supports this is the values of the (t) calculated for all the dimensions. Furthermore, the (P-value) for all the dimensions is less than the level of significance $((\alpha=0.05$. in the light of previous results, the null hypothesis (H02) will be rejected and the alternative hypothesis (H12) will be accepted. The last suggests that (there is a statistically significant impact at the level of significance $(\alpha \leq 0.05)$ for the dimensions of marketing Jordan regionally as a medical field).

$\mathrm{B}$ - The value of multiple correlation coefficient $(\mathrm{R})$ is (.723) that there is a strong and positive relationship that is statistically significant at the level of $(a=0.05)$ between the dimensions of availability and marketing Jordan as a medical center (regionally).

$\mathrm{C}$ - The value of the coefficient of explanation (R2) equaling (.721) indicates that the dimensions of the viability recourses for marketing Jordan as regional medical center equal (.721) table 6.

D - The standard transactions value calculated for the dimensions of availability recourse and marketing Jordan as a regional medical center, in table 8 the t-test was .818 , and significant .000 for military sector respectively. The increased interest in each dimension by one standard deviation, will improve the efficiency.

Finally, the author has preferred ordering the dimensions of the availability medical recourses affecting that there opportunities to marketing Jordan as a regional medical center according to the power of influence in order to figure out any dimension that is more influential on the performance of it depending on the standard transaction (BETA) that is calculated for the dimensions, as shown in table (8).

\section{Results}

The study showed the following results:

1: There are availability resources to marketing Jordan as a medical regional center (4 sectors, and nature sites).

2: There is no competition in the region.

3: a low level of government care to promote Jordan as a medical regional center

4: a low level of investment the medical resources in Jordan

5: the low degree of interaction between (government, private, Military) medical sectors

6: the plenty of efficiency and experience by the employees (6 medical faculties and 19 nursing faculties) 
7: The availability of medical sources had the largest impact on directing the marketing Jordan as a regional medical center.

8: The integration and coordination of sectors has a moderate power of effect.

9: Generally, the tourism marketing performance is affected with the various variables of the study moderately.

\section{Recommendations}

The study recommended the following:

1: Focusing on understanding the changes in the medical needs and desires of customers and there medical care

2: diversifying the the medical care in the different segments services to meet competition

3: increasing the attention to the complaints of customers and solving them

4: increasing the level of coordination between the various medical sectors

5: rehabilitating, training and raising the efficiency of employees

6: exploiting the competitive abilities of the medical care sector and targeting new market segments to enhance customer's number, profits

7: cooperate with various medical sectors on the fact that hold their moral and social responsibilities in line with the customers' requirements

\section{References}

Abu Rumman, A., \& Alrawe, A. (2009). Tourism in Jordan. Amman, Jordan: Dar Warraq for publication.

Aldmour \& Nuseirat. (2004). The impact of the marketing mixes to attract Arab patients for treatment in Jordanian hospitals. Civil Irbid National University Journal, 14(1).

Ali, K. (2007). Medical tourism in Jordan, a case study of Yemenis patients. University of Jordan, unpublished Master Thesis, Amman, Jordan.

Aljllad, A. A. (2005). Tourism and environmental planning. Cairo, Egypt: the world of books.

Almassaroh et al. (2006). The determinants of tourist demand in Jordan. Journal of Research and Studies, 21(5).

Al-Tai, H. (2001). The assets of the tourism industry. Amman, Jordan: Dar Warraq for publication.

Al-Tai, H. (2004). Tourism Marketing, a strategic entrance. Amman, Jordan: Dar Warraq for publication.

Barhoum, A. (2007). Evaluate the efficiency of tourism marketing in Syria. October Journal University, 29(2).

Bthathaw, I., \& Aldilain, A. (2011). E-marketing and tourist sites in Jordan therapeutic. Journal of the Federation of Arab Tourism and Hospitality, 7(1).

Ismail, S., \& Sheikh, M. (2010). The influence of the marketing of medical services of Jordan on the growth of medical tourism locally and the Arab world. Irbid National University Journal, 14(I).

Magableh, H. D. (2000). The tourism industry in Jordan (1st ed.). Amman, Jordan: Dar Wael for publication.

Maiah, K. (1995). Geography of medical tourism in Jordan. University of Jordan, unpublished Master Thesis, Amman, Jordan.

Mosharbash, D. G. (2008). Factors affecting the satisfaction of tourists for medical tourism in Jordan. University of Jordan, unpublished Master Thesis, Amman, Jordan.

Qoukzh, A. (2001). Patterns and trends of Arab tourism in Jordan. University of Jordan, unpublished Master Thesis, Amman, Jordan.

Saleh, S. (1994). Elements of tourist attractions in the city of Jeddah. King Abdul Aziz University, unpublished Master Thesis, Jeddah, Saudi Arabia.

Samawe, S. (2008). Tourism in Jordan. Amman, Jordan: Dar Al Zahraa for publication.

Suzan, S. (2000). Tourism business Internet marketing.

The Ministry of Tourism and Antiquities. (2003). National Strategy for Jordanian tourism from 2004 to 2010. Amman, Jordan.

The report of the World Tourism Organization. (2011). Statistics.

University of the Middle East. (2011). First International Conference on Tourism, Amman, Jordan. 
University of the Middle East. (2011). The concept of e-tourism. Tourism Magazine, 4(1).

UNWTO. (2008). World Tourism Barometer.

World Tourism Organization. (2009). Annual Report 2001-2009.

Yusuf, K. M. (2006). The tourism industry. Baghdad, Iraq: Dar Euphrates for publication.

\section{Appendix A}

Table 2. Reliability of scales

\begin{tabular}{lll}
\hline & N. Items & Alpha (a) \\
\hline Regional & 5 & 0.89 \\
GMS & 6 & 0.87 \\
Private & 5 & 0.75 \\
Military & 4 & 0.81 \\
n & 5 & 0.85 \\
GR & 4 & 0.79 \\
\hline
\end{tabular}

Table 3. Descriptive statistics

\begin{tabular}{llllll}
\hline & $\mathrm{N}$ & Minimum & Maximum & Mean & Std. Deviation \\
\hline Regional & 275 & 2 & 5 & 2.95 & .886 \\
GMS & 275 & 1 & 5 & 2.95 & .861 \\
Private & 275 & 1 & 5 & 2.78 & .828 \\
Military & 275 & 1 & 4 & 2.94 & .856 \\
Neutral & 275 & 1 & 4 & 2.94 & .858 \\
GR & 275 & 1 & 3 & 2.77 & .776 \\
Valid N (list wise) & 275 & & & & \\
\hline
\end{tabular}

Table 4. Correlations

\begin{tabular}{|c|c|c|c|c|c|c|c|}
\hline & & Regional & GMS & Private & Military & Neutral & GR \\
\hline \multirow[t]{3}{*}{ Regional } & Pearson Correlation & 1 & $.842(* *)$ & $.632\left(^{*}\right)$ & $.459(*)$ & $.661(* *)$ & $.733(* *)$ \\
\hline & Sig. (2-tailed) & & .000 & .014 & .042 & .002 & .000 \\
\hline & $\mathrm{N}$ & 275 & 275 & 275 & 275 & 275 & 275 \\
\hline \multirow[t]{3}{*}{ GMS } & Pearson Correlation & $.842(* *)$ & 1 & $.662(* *)$ & $.696(* *)$ & $.984(* *)$ & $.783(* *)$ \\
\hline & Sig. (2-tailed) & .000 & & .001 & .001 & .000 & .000 \\
\hline & $\mathrm{N}$ & 275 & 275 & 275 & 275 & 275 & 275 \\
\hline \multirow[t]{3}{*}{ Private } & Pearson Correlation & $.632(*)$ & $.662(* *)$ & 1 & $.730(* *)$ & $.656(* *)$ & $.460(*)$ \\
\hline & Sig. (2-tailed) & .014 & .001 & & .000 & .002 & .041 \\
\hline & $\mathrm{N}$ & 275 & 275 & 275 & 275 & 275 & 275 \\
\hline \multirow[t]{3}{*}{ Military } & Pearson Correlation & $.459(*)$ & $.696(* *)$ & $.730(* *)$ & 1 & $.722(* *)$ & .437 \\
\hline & Sig. (2-tailed) & .042 & .001 & .000 & & .000 & .054 \\
\hline & $\mathrm{N}$ & 275 & 275 & 275 & 275 & 275 & 275 \\
\hline \multirow[t]{3}{*}{ Neutral } & Pearson Correlation & $.661(* *)$ & $.984(* *)$ & $.656(* *)$ & $.722(* *)$ & 1 & $.732(* *)$ \\
\hline & Sig. (2-tailed) & .002 & .000 & .002 & .000 & & .000 \\
\hline & $\mathrm{N}$ & 275 & 275 & 275 & 275 & 275 & 275 \\
\hline \multirow[t]{3}{*}{ GR } & Pearson Correlation & $.733(* *)$ & $.783(* *)$ & $.460(*)$ & .437 & $.732(* *)$ & 1 \\
\hline & Sig. (2-tailed) & .000 & .000 & .041 & .054 & .000 & \\
\hline & $\mathrm{N}$ & 275 & 275 & 275 & 275 & 275 & 275 \\
\hline
\end{tabular}

Table 5. Colinearity statistics

\begin{tabular}{lll}
\hline \multirow{2}{*}{ Model } & Colinearity Statistics & \\
\cline { 2 - 3 } & Tolerance & VIF \\
\hline Regional & .632 & 1.451 \\
GMS & .735 & 1.365 \\
Private & .675 & 1.481 \\
Military & .705 & 1.414 \\
Neutral & .644 & 1.582 \\
GR & .634 & 1.360 \\
\hline
\end{tabular}


Table 6. Model summary

\begin{tabular}{lllll}
\hline Model & $\mathrm{R}$ & R Square & Adjusted R Square & Std. Error of the Estimate \\
\hline 1 & $.723^{\mathrm{a}}$ & .721 & .701 & .155 \\
\hline
\end{tabular}

a. Predictors: (Constant), GMS, Private, Military, Neutral, GR.

Table 7. ANOVA ${ }^{\mathrm{s}}$

\begin{tabular}{lllllll}
\hline Model & & Sum of Squares & df & Mean Square & F & Sig. \\
\hline 1 & Regression & 13.760 & 4 & 3.440 & 163.822 & $.000^{\mathrm{a}}$ \\
& Residual & .315 & 15 & .021 & & \\
& Total & 14.075 & 19 & & & \\
\hline
\end{tabular}

a. Predictors: (Constant), GMS, Private, Military, Neutral, GR.

b. Dependent Variable: Regional.

Table 8. Coefficients

\begin{tabular}{|c|c|c|c|c|c|c|}
\hline & & \multicolumn{2}{|c|}{ Unstandardized Coefficients } & \multicolumn{2}{|c|}{ Standardized Coefficients } & \multirow[b]{2}{*}{ Sig. } \\
\hline \multicolumn{2}{|c|}{ Model } & B & Std. Error & Beta & $\mathrm{t}$ & \\
\hline \multirow[t]{6}{*}{1} & (Constant) & .108 & .133 & & .807 & .432 \\
\hline & GMS & .040 & .049 & .048 & .818 & .011 \\
\hline & Private & .865 & .075 & .880 & 11.550 & .005 \\
\hline & Military & .040 & .049 & .048 & .818 & .000 \\
\hline & Neutral & 0.751 & .070 & 0.780 & 9.888 & .010 \\
\hline & GR & .097 & .043 & .130 & 2.249 & .005 \\
\hline
\end{tabular}

a. Dependent Variable: Regional.

\section{Appendix B. Questionnaire}

Greetings:

In this questionnaire I tried to spot light on tourism in Jordan through the study entitled "The availability to marketing Jordan as a regional medical service center"

From the standpoint of workers" your response will be used confidentially and for scientific research purposes only.

Researcher

Dr Mahmud Aqel Abu Dalbooh

Assistant marketing Professor

Irbid National University

Please answer these questions by putting $(\sqrt{ })$ in the right place:-

\section{A - Demographics features}

1 - Personal characteristics:

A - Age in Years: $30-39(\quad$ ) $40-49(\quad$ ) 50 and more

B - Gender: Male ( ) female ( )

C - Marital Status: Married ( ) unmarried ( )

D - Place of living: City ( ) town ( )

E-Religion: Muslim ( ) Otherwise ( ) 


\section{2 - General characteristics:}

A - Income JD: 1000 - less ( ） 1001-1500（） 1501 and more ( ）

B - Function: Director ( ) Administrative ( ) Medical employee ( )

C - Qualifications: Master degree ( ) Bachelor degree ( ) Community college or less ( )

D - Year experience: 10 or less ( ) 11 and more ( )

E - The nature of the work: Special ( ) general ( )

\section{B- Elements of the medical sector available in Jordan:}

\begin{tabular}{|c|c|c|c|c|c|}
\hline A. Government medical sector & $\begin{array}{l}\text { Strongly } \\
\text { agree }\end{array}$ & Agree & Neutral & Disagree & $\begin{array}{l}\text { Strongly } \\
\text { disagree }\end{array}$ \\
\hline \multicolumn{6}{|l|}{$\begin{array}{l}1 \text { - There are multiple medical sites in Jordan (hospitals, centers). } \\
2 \text { - Available new medical teqnology Jordan help marketing Jordan as a } \\
\text { regional medical center attraction. }\end{array}$} \\
\hline \multicolumn{6}{|l|}{$\begin{array}{l}3 \text { - Available excellent skills in Jordan help marketing Jordan as a regional } \\
\text { tourist attraction. }\end{array}$} \\
\hline \multicolumn{6}{|l|}{4 - Jordan has multiple medical specialties. } \\
\hline \multicolumn{6}{|l|}{5 - Jordan has multiple professional center. } \\
\hline \multicolumn{6}{|l|}{6 - There are excellent infrastructure which augmented the medical job. } \\
\hline \multicolumn{6}{|l|}{ B. Private medical sector. } \\
\hline \multicolumn{6}{|l|}{$\begin{array}{l}2 \text { - Available new medical teqnology Jordan help marketing Jordan as a } \\
\text { regional medical center attraction. }\end{array}$} \\
\hline \multicolumn{6}{|l|}{$\begin{array}{l}3 \text { - Available excellent skills in Jordan help marketing Jordan as a regional } \\
\text { tourist attraction. }\end{array}$} \\
\hline \multicolumn{6}{|l|}{4 - It has a good medical policy. } \\
\hline \multicolumn{6}{|l|}{5 - There are an appropriative infrastructure which augmented the medical job. } \\
\hline C. Military medical sector & & & & & \\
\hline
\end{tabular}

1 - There are many medical sites (hospitals, centers ,royal medical city)

2 - Available new medical technology Jordan helps marketing Jordan as a regional medical center attraction additionally regionally troops.

3 - Available excellent skills in Jordan help marketing Jordan as a regional medical center.

4 - There is an appropriative infrastructure which augmented the medical job.

\section{Natural medical sites}

1 - There are many natural medical sites (dead sea, hills, medical water).

2 - Available new medical hotels, motels, and medical places help marketing Jordan as a regional medical center attraction.

3 - Available excellent skills in Jordan help marketing Jordan as a regional tourist attraction.

4 - Jordan has multiple medical specialties sites which helping for attraction customers.

5 - There are an appropriative (medical sites) infrastructure which augmented the medical job.

\footnotetext{
E. The role of government

1 - Governmental institutions in the medical sector seeking to develop a strategy for marketing Jordan as a regional medical center.

2 - The government presses on private institutions sector to develop a strategy for marketing Jordan as a regional medical center.

3 - The governmental institutions develop its policies, programs and plans in accordance with the modern requirements for medical center.

4 - Governmental institutions are seeking to develop the medical sector and lead it to the level of the therapeutic industry.
} 


\section{Copyrights}

Copyright for this article is retained by the author(s), with first publication rights granted to the journal.

This is an open-access article distributed under the terms and conditions of the Creative Commons Attribution license (http://creativecommons.org/licenses/by/3.0/). 